\title{
Os estudos latinos no Brasil
}

\author{
EDUARDO TUFFANI \\ Universidade Federal Fluminense
}

\begin{abstract}
RESUMO: Trata-se da importância do ensino do Latim no período colonial, enfatizando o papel da Companhia de Jesus. É discutido o longo processo da reorganização do ensino secundário e da implantação dos estudos superiores. Apresenta-se a época que vai do fim do secundário de tradição literária à fundação dos primeiros cursos de Letras e Filosofia. Faz-se um balanço dos estudos latinos de 1940 a 1970, período de sua maior vitalidade no Brasil, tratando da Lei Capanema de 1942 e da antiga Lei de Diretrizes e Bases da Educação Nacional. É fechado o panorama com o relato das atividades até 1996, considerando o quadro por ocasião da nova LDB.
\end{abstract}

PALAVRAS-CHAVE: Latim; Brasil; ensino; história da educação.

Ainda que não seja o propósito deste trabalho historiar os estudos latinos no Brasil ${ }^{1}$, não se pode deixar de fazer um relato, mesmo breve, recuando até o século XVI. Com efeito, não se deve tratar o estudo do Latim no Brasil do mesmo modo que o do Direito e o da Medicina, cursos superiores implantados entre nós nas primeiras décadas do século XIX, ao passo que o Latim, desde o primeiro século da Colônia, era ensinado nas escolas secundárias. A instrução no Brasil dos primeiros séculos confundia-se com a presença da Companhia de Jesus, visto que, de 1549 a 1759, o ensino colonial esteve praticamente a cargo da Ordem. Ao contrário dos franciscanos, carmelitas e beneditinos, todos mais reclusos e ascéticos, os jesuítas faziam da educação um instrumento para a sua bandeira, o que em parte servia à expansão portuguesa (Azevedo, 1971, p. 511). Uma vez estabelecidos no país, os padres da Companhia passaram a fundar as escolas de ler e escrever, escolas elementares, e os seminários-escola ou colégios, escolas médias, em que se destacava o ensino do Latim. No momento da expulsão da Ordem em 1759 pelo Marquês de Pombal, havia na Colônia dezessete colégios mantidos pelos jesuítas, cinco dos quais eram seminários maiores de formação religiosa. Os colégios mais importantes eram o de Todos os Santos, na Bahia, e o de São Sebastião, no Rio de Janeiro²; ambos também contavam com os cursos de Filosofia e Teologia. No seminário-escola ou colégio, tinha vez o curso de Letras Humanas ou Humanidades; dele se suprimiu, inicialmente, o Grego em favor do Tupi Antigo numa adaptação da Ratio studiorum de Cláudio Acquaviva (Azevedo, 1971, p. 528). O curso de Filosofia e Ciências era intermediário, chamado "Colégio das Artes", com duração de três anos, na verdade um curso de Filosofia, sobretudo. De nível superior, o curso de Teologia e Ciências Sagradas, realizado em quatro anos, destinava-se à formação sacerdotal. 
A Metrópole não se dispôs a fundar no Brasil cursos superiores para especialidades como Direito e Medicina, fazendo com que os interessados, para fim de formação, se dirigissem à Universidade de Coimbra. O curso de Filosofia e Ciências da Colônia não logrou reconhecimento em Portugal, o que desestimulou a sua freqüência no Brasil, concentrando o ensino no curso de Letras Humanas. Assim sendo, o Colégio das Artes colonial acabou servindo como curso preparatório para o de formação religiosa. A partir do século XVIII, seminários diocesanos começaram a ser fundados, os dois primeiros em 1739 no Rio de Janeiro, seminários de São José e de São Pedro, sendo este depois dedicado a São Joaquim e refundado em 1837 como Colégio Pedro II. Com a expulsão da Companhia de Jesus, o ensino no Brasil praticamente se desorganizou, ficando reduzido aos seminários diocesanos e às escolas de fortificação, que vinham sendo fundadas desde o fim do século XVII ${ }^{3}$. Foi só em 1772 que o ensino no Brasil começou a se reorganizar com as cadeiras régias de nível secundário; entre elas foram estabelecidas as de Latim e também as de Grego. Na lentidão da reforma do ensino no Brasil, a fiscalização das escolas tornou-se regular só a partir de 1799, devendo-se registrar que, nessa fase de restabelecimento da instrução no Brasil, o ensino religioso levava vantagem sobre o oficial no que toca à eficiência (Azevedo, 1971, p. 551-552). Em 1776, os franciscanos fundaram um curso superior de Teologia no Rio de Janeiro, preenchendo o espaço deixado pela supressão dos cursos da Companhia. Digno de nota foi o Seminário de Olinda, fundado em 1798, que se consagrou como modelo de renovação do ensino secundário ${ }^{4}$.

A educação no Brasil só mudou de quadro de forma relevante com a transferência da corte portuguesa para o Rio de Janeiro. Em 1808, Dom João VI fundou a Impressão Régia, de que deriva a imprensa oficial brasileira ${ }^{5}$. A Biblioteca Nacional, por sua vez, teve origem numa biblioteca criada em 1810, a primeira pública, cujo acervo inicial proveio da Biblioteca Real da Ajuda. Em 1808, ano da chegada da corte, as escolas de cirurgia foram implantadas na Bahia e no Rio de Janeiro, evidenciando a situação em que, até o momento, o Brasil se encontrava. Os cursos de Engenharia foram organizados em 1810, enquanto os de Artes Plásticas e Arquitetura esperaram até 1826, estabelecimento da Academia das Belas-Artes, o que só ocorreu em pleno Império, depois de sucessivas fundações (1816, 1820, 1820 e 1826) (Morales de los Rios Filho, 1960, p. 374-375). Foi também só com a Independência do país que se fundaram os cursos de Direito, em 1827, em Olinda e em São Paulo. Após o Primeiro Reinado, durante o Período Regencial, o Brasil passou por uma nova fase de crescimento intelectual. O Ato Adicional de 6 de agosto de 1834 consolidou o ensino secundário no Brasil, ainda que de forma incipiente. Em 1837, foi fundado no Rio de Janeiro o Real Gabinete Português de Leitura, e, em 1838, foram criados o Arquivo Nacional e o Instituto Histórico e Geográfico Brasileiro. Segundo o Ato Adicional, o ensino primário e secundário estava a cargo das assembléias provinciais, com exceção da cidade do Rio de Janeiro, diretamente subordinada ao governo imperial, responsável também pela instrução de nível superior (apud Azevedo, 1971, p. 574). Datam da época as tradicionais escolas secundárias que passaram a manter o ensino oficial pelos grandes centros do país. Em 1837, reorganizado o Seminário de São Joaquim como Colégio Pedro II, estabeleceu-se no Rio de Janeiro a escola-modelo do ensino secundário no Brasil. Com a reforma estatutária de 1841, o curso passou de seis para sete anos, sendo o Grego estudado nos quatro primeiros, enquanto o estudo do Latim se fazia ao longo de todo o período (Azevedo, 1971, p. 578-579). Ao fim 
do curso, era conferido o grau de Bacharel em Letras, o que deveria ter lugar num curso superior de Letras; no entanto, apesar de ter sido proposto, tal curso nunca foi implantado durante o Império.

Com o advento da República, houve uma reforma geral da educação no Brasil. No que toca ao secundário, planejou-se um ensino enciclopédico, privilegiando as ciências exatas e físicas em prejuízo da formação clássica e literária. O Decreto de 2 de janeiro de 1891 reduziu o curso de sete para cinco anos, o que não se aplicou ao Colégio Pedro II então Ginásio Nacional, rompendo a unidade do secundário no país (apud Faria, 1959, p. 86-87). Com relação ao ensino superior, houve uma difusão dos cursos de Direito, Medicina e Engenharia pelas unidades federativas, proporcionada pela autonomia estadual. Além daqueles tradicionais, fundaram-se também cursos de outras especialidades, diversificando o quadro da instrução no Brasil. Um Estado que se destacou nessa fase de expansão da universidade foi São Paulo, novo pólo econômico do país, onde se fundaram, por iniciativa privada, as primeiras faculdades de Filosofia. A Universidade de Manaus, primeira nacional, foi criada em 1909, congregando as três faculdades tradicionais, uma Faculdade de Ciências e Letras, sendo esta uma escola secundária nos moldes do Ginásio Nacional com o bacharelado de Ciências e Letras (Passos, 1914), e uma Faculdade Militar de acordo com as escolas superiores militares, já que a Escola Universitária Livre de Manaus, nome de fundação, teve origem na Escola Livre de Instrução Militar do Amazonas. Ignorada em parte nos anais da educação, a Universidade de Manaus foi, com efeito, a primeira universidade brasileira. A Universidade do Rio de Janeiro foi organizada em 1920, e concorreram, para tanto, algumas das mais antigas faculdades brasileiras, às quais depois foram sendo outras anexadas.

Em 1908, foram instaladas as duas primeiras faculdades de Filosofia, ambas em São Paulo, sob orientação católica ${ }^{6}$. A Faculdade Eclesiástica de São Paulo, anexa ao Seminário Provincial, funcionou por seis anos com o bacharelado de Filosofia (Silva \& Silva, 1952, p. 25), encerrando as suas atividades em 1914. Na Faculdade Livre de Filosofia e Letras de São Paulo, também só era oferecido o curso de Filosofia, entendendo-se por "Letras" a Literatura, sobretudo de línguas modernas, e as Ciências Sociais e Históricas (Estatutos, 1909, p. 19). A Faculdade Livre de Filosofia e Letras era mantida pelo Mosteiro de São Bento, estando agregada, a partir de 1911, à Universidade de Louvain. Nos estatutos da Faculdade, previam-se futuras seções especiais de Letras e História (Extracto, 1911, p. 13), que só foram instituídas nas décadas seguintes. Em razão de sua antigüidade, a Faculdade de Filosofia de São Paulo, posteriormente de "São Bento", é a que mais se presta à história da implantação dos estudos superiores em Letras no Brasil.

A época próxima à Primeira Grande Guerra foi decisiva para a renovação dos estudos clássicos no país. A iminência da instalação das faculdades de Filosofia, a nova feição do curso secundário e a maior circulação das idéias e dos livros fizeram do momento o início de um período de transição nos estudos latinos no Brasil. Na fase anterior, o estudo do Latim se limitava ao seminário, ao secundário de tradição clássica e literária e ao curso jurídico com a cátedra de Direito Romano. A época produziu intelectuais de peso, grandes professores, tradutores e romanistas, homens públicos de cultura, como Manuel Odorico Mendes, Francisco Sotero dos Reis, João Gualberto Ferreira dos Santos Reis, Antônio Co- 
elho Rodrigues, Francisco Rodrigues dos Santos Saraiva, Antônio José de Sousa e César Zama, citando os mais representativos. Ao longo do período, os centros que mais se distinguiram nos estudos clássicos e romanísticos foram Recife, Rio de Janeiro, Salvador, São Luís e São Paulo. No início do século XX, Vicente de Souza, professor do Colégio Pedro II, divulgou um trabalho sobre a pronúncia reconstituída do Latim (Souza, 1902), demonstrando atualidade e antecipando a querela da pronúncia latina ${ }^{7}$, que marcou a fase posterior dos estudos latinos no país.

Em 12 de outubro de 1915, foi criada a Academia de Altos Estudos, vinculada ao Instituto Histórico e Geográfico Brasileiro, entre outras especialidades, contando com o curso de Filosofia e Letras. Neste curso de Filosofia, com duração de três anos, dedicava-se à Filologia um maior espaço (Estatutos, 1917, p. 4-5). Instalada em 1916, a Academia foi, três anos depois, reestruturada como Faculdade de Filosofia e Letras, ampliando a oferta de cursos. Entre as seções do Curso Normal Superior, encontrava-se, entre as de Letras, a de Línguas Clássicas (Latim e Grego) (Regulamento, 1919, p. 3); entretanto, até 1921, quando a Faculdade encerrou as suas atividades, os cursos de Letras não foram implantados. $\mathrm{O}$ vazio deixado pelo fim de tal centro foi ocupado em 1924 pela Faculdade de Filosofia do Rio de Janeiro, que manteve o seu curso de Filosofia em atividade até 1937 na então capital federal. Em 1925, a Faculdade de Filosofia de São Paulo passou a oferecer também o curso de Filologia Clássica (Latim e Grego) (Relatorio, 1925, p. 17-20), primeiro de Letras no Brasil. O curso era trienal e seu primeiro professor foi Alexandre Correia, bacharel pela mesma faculdade e doutor em Filosofia pela Universidade de Louvain. Os formandos de Filologia Clássica não recebiam o título de bacharel, mas um atestado de conclusão de curso (Regulamento, 1931, p. 100), visto que não havia legislação para os estudos superiores em Letras. A Lei Rocha Vaz de 1925 confirmou os cinco anos do secundário, com quatro de Latim da segunda à quinta série, mantendo o curso de um sexto ano para os aspirantes ao grau de Bacharel em Ciências e Letras (apud Faria, 1959, p. 87), cabendo à escola média a concessão do título de amparo legal. Em 1931, fundou-se a Faculdade de Letras e Filosofia de São Paulo, extinta um ano depois. Embora tenha deixado pouca documentação, pode-se afirmar que não teve um papel decisivo por não ter havido tempo para consolidar a sua atividade.

Ministro da Educação e Saúde Pública, Francisco Campos reformou o ensino universitário, criando a Faculdade de Educação, Ciências e Letras com o Decreto nº 19851, de 11 de abril de 1931. Com relação às faculdades de Filosofia, foi a primeira iniciativa oficial, amparada num Estatuto das Universidades Brasileiras; entretanto, reorganizada a Universidade do Rio de Janeiro, ficou a Faculdade por instalar. O curso secundário também foi reformado com o Decreto ${ }^{\circ} 19890$, de 18 de abril de 1931. Dividido em dois, mas ampliado para sete anos, cinco do curso fundamental e dois do complementar por especialidade, sendo ofertados quatro anos de Latim, dois no fundamental e dois na seção especial de Direito (Faria, 1959, p. 87-88). Em 1933, foi implantada em São Paulo a primeira faculdade de Filosofia segundo o Estatuto, o Instituto Superior de Filosofia, Ciências e Letras "Sedes Sapientiae", de orientação católica como a Faculdade de Filosofia de São Bento. Armando de Sales Oliveira, no governo do Estado de São Paulo, fundou a primeira faculdade oficial de Filosofia, a Faculdade de Filosofia, Ciências e Letras da Universidade de São Paulo, 
instituída esta em 1934 com a criação de novas faculdades e a reestruturação das unidades tradicionais. A exemplo dos cursos anteriores de Letras e Filosofia, o de Letras Clássicas e Português da USP tinha duração de três anos (Anu. Fac. Fil. Ci. Letras, 1934/1935, p. 289292), sendo Michel Berveiller o primeiro professor de Latim e Grego, já que a FFCL dispôs de uma missão de professores estrangeiros. Em 1935, fundou-se no Rio de Janeiro a Escola de Filosofia e Letras, integrando a então criada Universidade do Distrito Federal. Também contando com estrangeiros, no curso de Latim e Grego, a UDF teve Jacques Perret como professor de Latim, que fez escola com destaque para Ernesto Faria.

A Faculdade Nacional de Filosofia foi criada com o Decreto $n^{\circ} 452$, de 5 de julho de 1937, quando se converteu em Universidade do Brasil a Universidade do Rio de Janeiro, mas a FNF só foi instalada com o Decreto-Lei $n^{\circ} 1063$, de 20 de janeiro de 1939, que extinguiu a UDF, tranferindo os seus cursos para a Universidade do Brasil. O governo federal também padronizou os cursos superiores com o Decreto n 1190 , de 4 de abril de 1939. O curso de Letras Clássicas (Português, Latim e Grego) foi ampliado com um quarto ano para formação pedagógica, com o que se distinguia o bacharel do licenciado (Anu. Fac. Fil. Ci. Letras, 1939/1949, p. 15-16). O ano suplementar também serviu para especialização, possibilitando o curso de um quarto ano de Língua e Literatura Latina (Anu. Fac. Fil. Ci. Letras, 1951, p. 257). Em 1940, o Conselho Nacional de Educação reconheceu os cursos da Faculdade de Filosofia de São Bento (O reconhecimento, 1940, p. V-VI), uma vez pautados pelo Decreto $n^{\circ} 1190$. No curso de Letras Clássicas de São Bento eram então professores de Latim e Grego, respectivamente, Polycarpo Amstalden e José Rodrigues dos Santos. Daí em diante, criaram-se mais cursos superiores de Letras, ficando para trás a fase do bacharelado em Ciências e Letras.

Com a consolidação do ensino universitário, os estudos latinos no país assumiram outra dimensão. Nota-se a profusão de artigos e resenhas em revistas de cultura, como $A$ Ordem, Revista de Cultura e Vozes de Petrópolis, as três de inspiração católica. O número de traduções e de livros didáticos aumentou sensivelmente, devendo-se registrar os nomes de Augusto Magne, Leopoldo Pereira e João Ravizza, o primeiro e o último também autores das gramáticas mais elaboradas do período. O curso secundário mostrou vitalidade, contribuindo para o debate com as teses de concurso, entre o que merecem destaque os trabalhos de Hahnemann Guimarães e de Nelson Roméro. No ensino superior, formaram quadro Jacques Perret e Ernesto Faria, na UDF e na Universidade do Brasil, e, na USP, Rebêlo Gonçalves, entre outros, deu nova orientação aos estudos clássicos. Dos intelectuais dessa época, deve-se mencionar o romanista Abelardo Saraiva da Cunha Lobo e o humanista Fernando de Azevedo, sociólogo e pedagogo.

A Lei Capanema de 1942 coincidiu com um novo momento dos estudos latinos no Brasil. Uma fase próspera que, ao mesmo tempo, apresentava a sua contrapartida. A Lei Capanema ampliou para sete anos o ensino do Latim no secundário, nas quatro séries do Ginásio e nas três do Clássico do Colegial (apud Nóbrega, 1962, p. 457). Como não havia um quadro de professores habilitados, a demanda foi suprida de modo improvisado (Nóbrega, 1962, p. 461), permitindo um ato ministerial que os licenciados em Letras Neolatinas e Anglo-Germânicas também lecionassem Latim (Faria, 1959, p. 288), o que tornou o ensino desigual e mesmo insatisfatório. Um expoente dos latinistas, Vandick L. da Nóbrega, re- 
conheceu o efeito negativo da Lei Capanema (Nóbrega, 1962, p. 461). Na execução da Lei de Diretrizes e Bases da Educação Nacional, em 1962, tornado facultativo o Latim no secundário, ficou evidente que o seu ensino se mantinha por força de lei, uma vez que, a partir daí, caminhou para a quase total extinção. A tripla licenciatura de Português, Latim e Grego não sobreviveu a essa década, após o que o Latim na universidade se limitou às disciplinas obrigatórias dos cursos de Letras e à graduação opcional em Língua e Literatura Latina. A vitalidade dos estudos latinos no período que vai grosso modo de 1940 a 1970 não deve ser atribuída à Lei Capanema, salvo o maior volume de livros didáticos, é o resultado do amadurecimento conseguido ao longo das primeiras décadas do século XX.

Por ocasião da Lei de Diretrizes e Bases, havia no país três grandes associações de classicistas, cada uma com revista ou coleção especializada: Boletim de Estudos Clássicos da Associação de Estudos Clássicos do Brasil, Graeca \& Latina da União Nacional de Cultura Greco-Latina e Romanitas da Sociedade Brasileira de Romanistas. Com a expansão das faculdades de Filosofia, criaram-se revistas que abriram espaço para a publicação de artigos e resenhas elaborados pelos professores de Letras Clássicas. As teses de concurso e da carreira universitária continuaram a ser o meio de ascensão e de formação profissional. Com relação ao nível universitário, os trabalhos publicados mostraram um avanço contínuo. A querela da pronúncia dominou grande parte do período e foi, para prejuízo dos estudos latinos, tratada de forma apaixonada e intransigente com muito desgaste para as partes envolvidas. Entre os defensores da pronúncia reconstituída, destacaram-se J. Mattoso Câmara Jr., Ernesto Faria e Serafim da Silva Neto. A pronúncia tradicional foi amparada sobretudo por Cândido Jucá Filho, J. F. Marques Leite e Nelson Roméro. Dos autores de livros didáticos, merecem destaque Júlio Comba e Napoleão Mendes de Almeida pela grande aceitação de seus manuais. Quanto à tradução de textos latinos, entre as muitas contribuições, citam-se as de Arduíno Bolivar, Jaime Bruna, João Evangelista Enout, Maximiano Augusto Gonçalves, Agostinho da Silva e Tassilo Orpheu Spalding. Arrolando os latinistas que se projetaram pelos seus trabalhos ou pela formação de pessoal, mencionam-se, além dos citados, Paulo Evaristo Arns, Evanildo Bechara, Laurindo Dias Bicalho, Cláudio Brandão, Junito de Souza Brandão, Otávio T. de Brito, Heinrich A. W. Bunse, Antônio Pinto de Carvalho, Aída Costa, Ismael de Lima Coutinho, Sílvio Elia, José Lourenço de Lima, Augusto Magne, Theodoro Henrique Maurer Junior, Salvatore D'Onofrio, Alfredo Xavier Pedroza, R. C. Romanelli, Abílio de Jesus dos Santos, Olmar Guterres da Silveira, Maria Evangelina Soeiro, Armando Tonioli, Dante Tringali, Mílton Valente e Maria Amélia de Pontes Vieira. A Faculdade de Filosofia de São Bento e o Instituto "Sedes Sapientiae" integraram a Universidade Católica de São Paulo, fazendo parte de sua escola L. Van Acker, Neyde Ramos de Assis, Adelino José da Silva d'Azevedo, José van den Besselaar, Bento Prado de Almeida Ferraz, Enio Aloisio Fonda, G. D. Leoni e Celestino Correia Pina. A cadeira de Direito Romano em muito contribuiu para o avanço dos estudos latinos, nela sobressaindo Alexandre Correia, Sílvio A. B. Meira, Elpidio Ferreira Paes, Vandick L. da Nóbrega e J. Lourenço de Oliveira, os dois últimos também professores de Língua Latina, respectivamente, no Colégio Pedro II e na Universidade de Minas Gerais. Na impossibilidade de continuar a listagem ${ }^{8}$, menciono A. Marques de Oliveira Filho, evocando os latinistas brasileiros com um nome, o de um profissional a quem não se deu o devido reconhecimento (Freitas, 1990). 
Por volta de 1970, o ensino do Latim no Brasil estava reduzido aos seminários e aos cursos de Letras. Quanto ao ensino primário e secundário, houve uma reforma, no início da década seguinte, que o reorganizou em dois graus, um primeiro de oito anos e um segundo de três anos de duração. Dez anos após a Lei de Diretrizes e Bases, o Latim havia praticamente desaparecido no ensino secundário, constituindo notória exceção, entre outros estabelecimentos, o tradicional Colégio Pedro II. Nos cursos de Letras, a graduação em Língua e Literatura Latina não se manteve sequer nas universidades católicas, permanecendo somente nas instituições públicas com tradição nos estudos latinos. No começo dessa década, terminaram os cursos de pós-graduação nos moldes antigos. Na USP, Aída Costa em Letras e Eurípedes Simões de Paula em História reestruturaram os cursos de acordo com a nova orientação. Na Universidade Federal do Rio de Janeiro, antiga Universidade do Brasil, Américo da Costa Ramalho, da Universidade de Coimbra, destacou-se no curso de pósgraduação por ter consolidado a linha de pesquisa dedicada ao Latim do Renascimento. Em 1972, Enio Aloisio Fonda criou o Arquivum Generale Poetarum Latinorum Brasiliensium na então Faculdade de Filosofia, Ciências e Letras de Assis, incorporada posteriormente à Universidade Estadual Paulista. Nos anos oitenta, com a implantação do curso de pós-graduação no Campus de Assis, desenvolveu-se a linha de pesquisa relativa à Latinidade Brasileira.

A Sociedade Brasileira de Estudos Clássicos foi criada em 1985 a partir de um evento realizado em 1984 por iniciativa de professores do Departamento de Letras Clássicas da Universidade Federal de Minas Gerais. Desde então, os membros da SBEC vêm-se congregando periodicamente em reuniões e simpósios. A partir de 1987, o grupo de trabalho "Latim e Grego na Universidade Brasileira" tem-se reunido com normalidade nos encontros da Associação Nacional de Pós-Graduação e Pesquisa em Letras e Lingüística. Em 1981, cessou o periódico Romanitas, que teve à frente Vandick L. da Nóbrega, cujo trabalho editorial prosseguiu então com a revista Omnia, publicação da extinta Faculdade de Humanidades Pedro II. Na UFRJ, a helenista Guida Nedda Barata Parreiras Horta dirigiu a revista Calíope da associação de estudos clássicos homônima, valendo registrar que, nessa universidade, teve sede primeiramente a Sociedade Brasileira de Estudos Latinos, fundada por Ernesto Faria. A SBEC se consagrou como a única grande associação em nível nacional, situação diferente da vivenciada nos anos cinqüenta e sessenta. Quanto à produção acadêmica, a SBEC vem publicando os anais de seus eventos, a revista Classica e a coleção Textos de Cultura Clássica.

No fim de 1996, foi sancionada a nova Lei de Diretrizes e Bases da Educação Nacional, facultando o Latim no ensino superior, o que trouxe apreensão aos latinistas brasileiros. Analisando o quadro de forma desapaixonada, entende-se que a situação do Latim em 1942 e em 1996 tem algo em comum, a obrigatoriedade do ensino e a formação desigual do professor nomeado. Em 1996, havia 389 cursos de Letras ${ }^{9}$; no entanto, para a graduação do latinista, existia uma dezena de cursos, em sua maioria, concentrada nos Estados de Minas Gerais, Rio de Janeiro e São Paulo. Deve-se compreender que, desde os tempos de Gustavo Capanema, em se tratando de ensino, a expansão indiscriminada pode levar à improvisação do profissional, o que não contribui para o fomento dos estudos latinos (Nóbrega, 1962, p. 461). No caso do ensino superior, a habilitação exigida varia segundo os editais de seleção 
e concurso, mas, para o bom desempenho do professor, são necessários alguns anos de amadurecimento (Costa, 1972/1973, p. 460).

O quadro não deve ser considerado desanimador, porque o desafio está em garantir a qualidade do ensino do Latim com vista à sua difusão. Nos anos noventa, as graduações de Latim e Grego foram reativadas na Universidade Federal Fluminense. Na Universidade Estadual de Campinas, onde as Letras Clássicas limitavam-se ao Latim do currículo mínimo, o quadro foi ampliado, inclusive com professores de Grego, adquirindo-se importante biblioteca. Os cursos de Letras Clássicas de outras regiões devem ser preservados e incentivados, sendo necessária muita prudência na abertura de novas graduações. No que diz respeito ao ensino primário e secundário, seria interessante que o Latim tivesse o mesmo tratamento dispensado ao Grego anteriormente. O que não é impossível, haja vista o Colégio Pedro II, que manteve, décadas após a antiga Lei de Diretrizes e Bases, o ensino facultativo do Latim e do Grego em suas unidades escolares. Tem havido experiências bem sucedidas de implantação do Latim em estabelecimentos particulares de ensino médio e até fundamental. Os seminários menores e maiores também merecem atenção no incentivo aos estudos clássicos, uma vez que sempre foram ligados à preservação da herança romana. É preciso tratar a questão do Latim de forma serena e evitar posições extremadas que levam a distorções pouco defensoras da cultura clássica.

\section{Notas}

1 - Planejo incluir este panorama histórico na versão definitiva do Repertório brasileiro de língua e literatura latina (1830-1996).

2 - O colégio instalado em 1567 no Rio de Janeiro tinha sido fundado originalmente em 1549 em São Vicente, transferido em 1554 para Piratininga (Colégio de São Paulo), estando de novo em 1561 em São Vicente até a sua transferência definitiva (Azevedo, 1971, p. 511-512).

3 - As "Aulas de Fortificação" foram instituídas em 1699 na Bahia e no Rio de Janeiro e em 1739 em Pernambuco. Em 1792, a escola do Rio de Janeiro se tornou a Real Academia de Artilharia, Fortificação e Desenho, e Dom João VI, em 1810, a organizou como Academia Real Militar, origem da engenharia civil e militar brasileira.

4 - Criado em 1798, mas só implantado em 1800. Mantive as datas de fundação apenas quando não muito distantes das do real estabelecimento

5 - A imprensa fora introduzida em 1747 no Rio de Janeiro, sob Gomes Freire de Andrade, futuro Conde de Bobadela, mas tal iniciativa foi reprimida pela Metrópole.

6- Para o estudo das primeiras faculdades de Filosofia, assunto não tratado ainda de forma satisfatória; uma boa referência é, embora não exaustiva, Américo Jacobina Lacombe, Introdução ao estudo da história do Brasil (Lacombe, 1974, p. 151-157).

7 - Anteriormente, Júlio Ribeiro, professor de Latim em curso anexo à Faculdade de Direito de São Paulo, deixara uma Nova grammatica da lingua latina (Ribeiro, 1895), obra póstuma, inacabada, mas de rigor científico, com nova orientação para a pronúncia do Latim.

8 - Só estão citados os especialistas com trabalho de destaque até os anos sessenta. Em virtude da delimitação do objeto trabalhado no Repertório, autores latinos anteriores ao Renascimento Carolíngio, fica sem tratamento aqui a Latinidade Brasileira. No entanto, dos séculos XIX e XX, mencionam-se, entre tantos, os seguintes poetas latinos: Joaquim Luís Mendes de Aguiar, 
Francisco de Aquino Correia, José Francisco Correia, J. F. Marques Leite, Antônio de Castro Lopes, Caetano Oricchio e Pedro Sarnel.

9 - Desse total, 151 cursos eram oficiais: 78 estaduais, 57 federais e 16 municipais.

\section{Referências bibliográficas}

ANUARIO DA FACULDADE DE FILOSOFIA, CIÊNCIAS E LETRAS. São Paulo: Revista dos Tribunaes, Universidade de São Paulo, 1934/1935-1951.

AZEVEDO, Fernando de. A cultura brasileira. 5. ed. rev. ampl. São Paulo: Melhoramentos, Universidade de São Paulo, 1971.

COSTA, Aída. Língua e literatura latina e pós-graduação. Alfa, Marília: FFCL de Marília, v. 18/19, p. 451-460, 1972/1973.

ESTATUTOS da Academia de Altos Estudos. Rio de Janeiro: Imprensa Nacional, 1917.

ESTATUTOS da Faculdade Livre de Philosophia e Lettras de S. Paulo. Annuario da Faculdade Livre de Philosophia e Lettras de S. Paulo, São Paulo, v. 2, p. 19-23, 1909.

EXTRACTO dos estatutos da Faculdade Livre de Philosophia e Lettras de S. Paulo. Annuario da Faculdade Livre de Philosophia e Lettras de S. Paulo, São Paulo, v. 3, p. 11-15, 1911.

FARIA, Ernesto. Introdução à didática do latim. Rio de Janeiro: Acadêmica, 1959.

FREITAS, Horácio Rolim de. Um mestre ainda desconhecido: Alfredo Marques de Oliveira Filho. In: ESTUDOS universitários de lingüística, filologia e literatura: homenagem da Academia Brasileira de Filologia e do Círculo Lingüístico do Rio de Janeiro ao Prof. Dr. Sílvio Elia. Rio de Janeiro: Sociedade Brasileira de Língua e Literatura, 1990. p. 101-108.

LACOMBE, Américo Jacobina. Introdução ao estudo da história do Brasil. São Paulo: Nacional, Universidade de São Paulo, 1974.

MORALES DE LOS RIOS FILHO, Adolfo. Teoria e filosofia da arquitetura. Rio de Janeiro: Borsoi, 1960. t. 2.

NÓBREGA, Vandick L. da. A cultura clássica no Brasil. Romanitas: Revista de Cultura Romana (Língua, Instituições e Direito), Rio de Janeiro, v. 5, p. 457-465, 1962.

PASSOS, Astrolabio. Relatorio geral da Universidade de Manáos apresentado á Congregação da mesma Universidade. Archivos da Universidade de Manáos, Manáos, v. 4, n. 3, p. 71, jul./dez. 1914.

O RECONHECIMENTO dos cursos de filosofia, ciências sociais, letras clássicas e pedagogia. Revista da Faculdade de Filosofia, Ciências e Letras de São Bento, São Paulo, v. 1, p. V-VI, nov. 1940.

REGULAMENTO da Faculdade de Philosophia e Letras (Antiga Academia de Altos Estudos). Rio de Janeiro: Imprensa Nacional, 1919.

REGULAMENTO interno da Faculdade de Filosofia e Letras de São Bento. Revista da Faculdade de Filosofia e Letras de São Bento, S. Paulo, v. 4, p. 99-102, mar. 1931.

RELATORIO sobre o movimento da Faculdade de Philosophia e Letras, durante o anno lectivo de 1925. Annuario Faculdade de Philosophia e Letras de São Paulo, São Paulo, v. 12, p. 17-20, 1925. 
RIBEIRO, Julio. Nova grammatica da lingua latina. S. Paulo: King, 1895.

SILVA, Lauro Monteiro de Carvalho e \& SILVA, Maximiano de Carvalho e (Org.). Monsenhor Maximiano da Silva Leite: 1902 - 28 de outubro - 1952: poliantéia comemorativa do 50 aniversário de sua ordenação sacerdotal. Mogi-Mirim: Cardona, 1952.

SOUZA, Vicente de. Restituição da pronuncia latina: conforme os trabalhos de G. Edon, Fr. Bücheler, C. Juret, G. Freund, Fr. Bopp, Encyclopedie Moderne, etc. Rio de Janeiro: Laemmert, 1902.

TUFFANI, Eduardo. Les études latines au Brésil. Classica, São Paulo, 13/14, p. 393-402, 2000-2001.

RÉSUMÉ: II s'agit de l'importance de l'enseignement du Latin à la période colonial, surtout du rôle de la Compagnie de Jésus. On discute le long processus de la réorganisation de l'enseignement secondaire et des débuts des études supérieures. On présente l'époque de la fin du secondaire de tradition littéraire à la fondation des premiers cours de Lettres et Philosophie. On apprécie les études latines de 1940 à 1970, leur période la plus importante au Brésil, en traitant la Lei Capanema de 1942 et l'ancienne Lei de Diretrizes e Bases da Educação Nacional. Le panorama se termine par le rapport des activités jusqu'à 1996, et on considère le cadre lors de la nouvelle LDB.

MOTS-CLÉS: Latin; Brésil; enseignement; histoire de l'éducation. 